\title{
Penerapan Augmented Reality pada Sistem Operasi Android untuk Pengenalan Hewan Mamalia
}

\author{
Isa Oktaviani $^{\# 1,}$ Tursina $^{\# 2}$, Anggi Srimurdianti Sukamto ${ }^{\# 3}$ \\ "Program Studi Teknik Informatika Universitas Tanjungpura \\ Jl. Prof. Dr. H. Hadari Nawawi Pontianak 78124 \\ ${ }^{1}$ isaoktavianilo@gmail.com \\ ${ }^{2}$ tursinaeinformatika.untan.ac.id \\ ${ }^{3}$ anggidianti@informatika.untan.ac.id
}

\begin{abstract}
Abstrak - Teknologi dimanfaatkan manusia dalam berbagai bidang untuk membantu menyelesaikan kegiatan yang dulunya dikerjakan secara manual. Dengan memanfaatkan teknologi, aktivitas tersebut dapat diselesaikan dengan mudah dan cepat. Teknologi yang saat ini berkembang adalah Augmented Reality (AR) karena tampilan visual yang menarik sehingga dapat menampilkan objek 3 dimensi beserta animasinya dan terlihat seperti ada pada dunia nyata. Oleh karena itu, AR dapat digunakan untuk pengenalan hewan mamalia. Saat ini untuk pengenalan hewan mamalia hanya dapat dipelajari dari buku, video, dan internet. Maka, pada penelitian ini dibangun aplikasi AR untuk pengenalan hewan mamalia yang disertai dengan suara sehingga informasi yang disampaikan lebih detail. Untuk membangun aplikasi berbasis android, digunakan Unity sedangkan pembuatan aplikasi AR digunakan Vuforia SDK. Marker terdapat pada sebuah buku untuk menampilkan visualisasi objek 3D. Aplikasi yang dibangun pada sistem operasi android dengan menerapkan teknologi Augmented Reality bertujuan untuk pengenalan hewan mamalia kepada anak usia 7 hingga 12 tahun yang dapat menambahkan visualisasi objek 3D ke dalam lingkungan nyata sehingga mereka dapat mengenal hewan mamalia tersebut. Berdasarkan hasil pengujian jarak ideal, semakin terlihat pixel pada marker maka semakin berpengaruh pada sistem untuk menampilkan objek 3D. Berdasarkan hasil pengujian validity, anak-anak dapat mengenali hewan mamalia dengan menggunakan aplikasi AR Pengenalan Hewan Mamalia dengan hasil 91\% responden menjawab Sangat Baik. Oleh karena itu, Aplikasi AR Pengenalan Hewan Mamalia ini dapat dimanfaatkan pengguna sebagai media untuk mengenal hewan mamalia.
\end{abstract}

Kata kunci-Hewan Mamalia, Augmented Reality, Android, Unity, Unified Modeling Language (UML)

\section{Pendahuluan}

Teknologi memiliki peran penting bagi kehidupan manusia dalam berbagai bidang. Oleh karena itu, teknologi dimanfaatkan manusia untuk menyelesaikan pekerjaan yang dulunya dilakukan secara manual tetapi dengan bantuan teknologi pekerjaan tersebut dapat diselesaikan dengan mudah dan cepat. Teknologi yang sedang berkembang dan banyak digunakan saat ini adalah Augmented Reality (AR) karena dapat membuat suatu hal di dunia nyata menjadi 3D atau visual. Penggunaan teknologi dalam bidang edukasi sangatlah banyak seperti pembelajaran biologi [1], kimia [2], fisika, dan lain sebagainya. Selain itu, ada pula untuk mengenal hewan menggunakan teknologi AR karena saat ini untuk pengenalan hewan hanya dapat dipelajari dari buku, video dan internet sehingga diperlukan teknologi tambahan agar proses mengenal hewan lebih mudah dengan tampilan 3Dnya.

Augmented Reality bertujuan untuk mengembangkan teknologi yang memperbolehkan penggabungan secara realtime terhadap digital content yang dibuat oleh komputer dengan dunia nyata [3]. Benda-benda maya berfungsi menampilkan informasi yang tidak dapat diterima oleh manusia secara langsung. Hal ini membuat AR sangat berguna sebagai alat untuk membantu persepsi dan interaksi penggunanya dengan dunia nyata. Pesan dari dunia maya dapat memberikan manfaat bagi pengguna dalam aktivitas sehari-hari. Teknologi yang ditemukan sejak tahun 1957 oleh Morton Heilig selalu berkembang sehingga pada tahun 1975 pengguna dapat berinteraksi dengan obyek virtual[4]. AR yang begitu membantu aktivitas sehari-hari terus dikembangkan hingga saat ini.

Ada beberapa cara yang dapat digunakan untuk pengenalan hewan. AR merupakan cara lain yang dapat diterapkan untuk pengenalan hewan mamalia agar objek 
ditampilkan lebih nyata sehingga akan memudahkan bagi pengguna mengenali hewan mamalia tersebut. Saat ini memang sudah diluncurkan beberapa product pengenalan hewan yang dijual bebas, tetapi hanya sebatas penyebutan nama, gerak tubuh dan suara saja. Sementara yang akan diteliti adalah pengenalan hewan mamalia untuk memberikan informasi singkat seputar hewan tersebut dan pengenalan bagian tubuh, jenis makanan yang disertai dengan suara.

\section{URAIAN PENELITIAN}

Penelitian tentang penerapan teknologi AR dalam bidang edukasi sudah pernah dilakukan oleh peneliti lain. Seperti aplikasi Augmented Reality sebagai Media Pembelajaran Tata Surya[5]. Penelitian tersebut memanfaatkan 3D Max dan Unity 3D untuk membuat objek 3D, sedangkan pembuatan aplikasinya menggunakan software ARSound.

Selain itu ada pula Implementasi Augmented Reality sebagai Media Pembelajaran Interaktif yang kemudian diterapkan untuk pengenalan perangkat keras komputer pada mata kuliah Organiasi Arsitektur Komputer (OAK) di STMIK Palcomtech[6]. Penelitian ini menggunakan marker untuk pembuatan aplikasinya sedangkan untuk pengembangan sistem ia menggunakan waterfall. Kemudian ada Analisis dan Implementasi Metode Marker Base Tracking pada Augmented Reality Pembelajaran Buah-buahan[7]. Penelitian ini menganalisis parameter apa saja yang dapat menyebabkan marker tidak dapat muncul pada aplikasi AR.

\section{A. Augmented Reality (AR)}

Augmented Reality bertujuan untuk mengembangkan teknologi yang memperbolehkan penggabungan secara realtime terhadap digital content yang dibuat oleh komputer dengan dunia nyata[3]. AR memperbolehkan pengguna melihat objek maya dua dimensi atau tiga dimensi yang diproyeksikan terhadap dunia nyata yang tidak dapat dideteksi langsung oleh indera manusia atau yang biasa dikenal dengan mediated (termediasikan)[8]. (Emerging Technologies of Augmented Reality: Interfaces and Design).

\section{B. Android}

Android adalah sistem operasi disematkan pada gadget, baik itu handphone, tablet, juga sekarang merambah ke kamera digital dan jam tangan[9]. Android dikembangkan oleh Google Inc.

Android adalah sistem operasi untuk telepon seluler yang berbasis Linux. Android menyediakan platform terbuka bagi para pengembang buat menciptakan aplikasi mereka sendiri untuk digunakan oleh bermacam peranti bergerak. Awalnya, Google Inc. membeli Android Inc., pendatang baru yang membuat peranti lunak untuk ponsel.

\section{Unified Modelling Language (UML)}

Unified Modelling Language (UML) adalah sebuah "bahasa" yang telah menjadi standar dalam industri untuk visualisasi, merancang dan mendokumentasikan sistem piranti lunak[10]. UML menawarkan sebuah standar untuk merancang model sebuah sistem". UML hanya berfungsi untuk melakukan pemodelan. Jadi, penggunaan UML tidak terbatas pada metodologi tertentu, meskipun pada kenyataannya UML paling banyak digunakan pada metodologi berorientasi objek.

\section{Blender}

Blender adalah salah satu software open source yang digunakan untu membuat konten multi objek khususnya 3 dimensi. Kelebihannya antara lain open source, free, update, ringan, multi platform, dan memiliki fitur yang lengkap[11]. Blender ini dapat digunakan untuk membuat objek 2D maupun 3D yang disertai dengan animasi[12]. Objek inilah yang nantinya dijadikan sebagai marker. Dalam penelitian ini, digunakan adalah Marker Based Tracking. Namun, marker juga dapat menggunakan Markerless untuk memberikan informasi museum Kalimantan Barat berbasis Android[13].

\section{E. Unity}

Unity adalah sebuah game engine yang memungkinkan seseorang mau pun tim, untuk membuat sebuah Games 3D dengan mudah dan cepat[14]. Unity berbasis cross-platform, Unity dapat digunakan untuk membuat sebuah game yang bisa digunakan pada perangkat komputer, smartphone Android, iPhone, PS3, dan bahkan X-BOX. Unity adalah sebuah sebuah tool yang terintegrasi untuk membuat game, arsitektur bangunan dan simulasi, serta bisa untuk Games PC dan games Online [15].

\section{F. Hewan Mamalia}

Hewan Mamalia merupakan satu-satunya jenis binatang yang memiliki rambut di tubuhnya. Mamalia biasanya menyusui anaknya, karena itu hewan mamalia juga biasa disebut dengan hewan menyusui[16]. Secara umum, hewan mamalia dapat dinyatakan sebagai hewan bertulang belakang, berdarah panas, dan juga menyusui. Hewan mamalia selalu diidentikkan sebagai hewan yang melahirkan. Padahal, tidak semua hewan mamalia berkembang biak dengan cara melahirkan, ada pula hewan mamalia berkembangbiak dengan cara bertelur.

\section{G. Validity}

Validitas berasal dari kata validity yang mempunyai arti sejauh mana ketepatan dan kecermatan suatu alat ukur dalam melakukam fungsi ukurannya yang menunjukkan bahwa variabel yang diukur memang benar-benar variabel yang hendak diteliti oleh peneliti [17]. Pengujian validitas item ditunjukkan dengan adanya korelasi atau dukungan terhadap item total (skor total). Setiap pengguna akan memberikan skor angka terhadap aplikasi yang diuji kemudian persentasenya akan dihitung dengan metode linkert. Menurut Sugiyono (2012), Metode Linkert merupakan metode pengukuran yang digunakan untuk mengukur sikap, pendapat dan persepsi seseorang atau kelompok orang tentang fenomena sosial[18]. 


\section{PERANCANGAN SISTEM}

A. Metodologi Penelitian

Dalam penelitian ini dilakukan dengan beberapa tahapan, yakni studi literatur, analisis kebutuhan, pengumpulan data, rekonstruksi objek 3D, perancangan aplikasi, pembuatan aplikasi, pengujian aplikasi, analisis hasil pengujian dan penarikan kesimpulan.

B. Perancangan Unified Modeling Language (UML)

1) Use Case Diagram

Use Case diagram merupakan pemodelan untuk kelakuakn (behavior) sistem informasi yang akan dibuat. Use case digunakan untuk mengetahui fungsi apa saja yang ada di dalam sistem informasi dan siapa saja yang berhak menggunakan fungsi-fungsi tersebut[19]. Diagram use case berikut menggambarkan perilaku aktor yang terlibat dalam aplikasi. Dalam aplikasi ini user dapat melakukan perilaku yaitu memilih menu seperti menu Panduan, menu AR Kamera, menu Tentang dan menu Keluar. Use Case diagram dalam penelitian ini dapat dilihat pada Gambar 1 berikut ini.

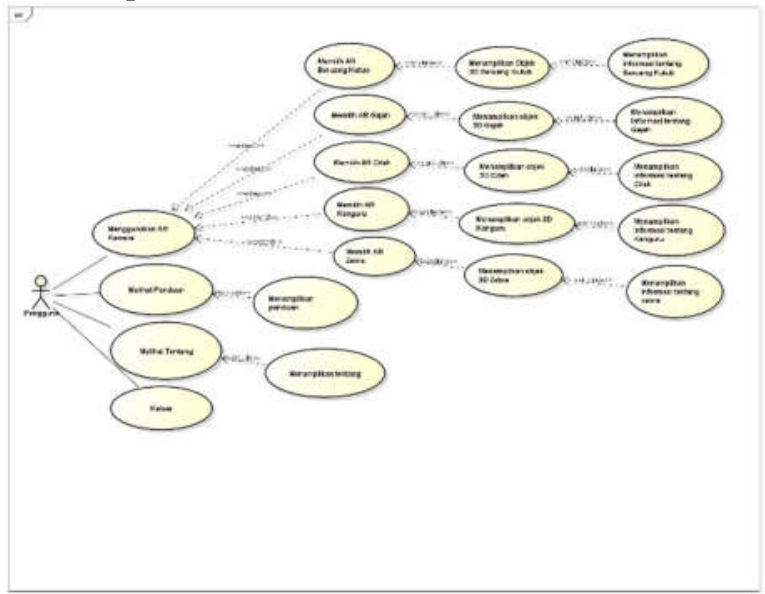

Gambar 1 Use Case Diagram

2) Activity Diagram

Activity diagram menggambarkan alir aktivitas dalam sistem yang dirancang yang melibatkan tindakan user atau pengguna dalam menggunakan aplikasi[20]. Activity diagram dimulai dari awal aplikasi dijalankan kemudian pengguna atau user memilih menu Panduan, menu AR Kamera, menu Tentang, hingga pengguna menghentikan aplikasi. Activity diagram dapat dilihat pada Gambar 2.

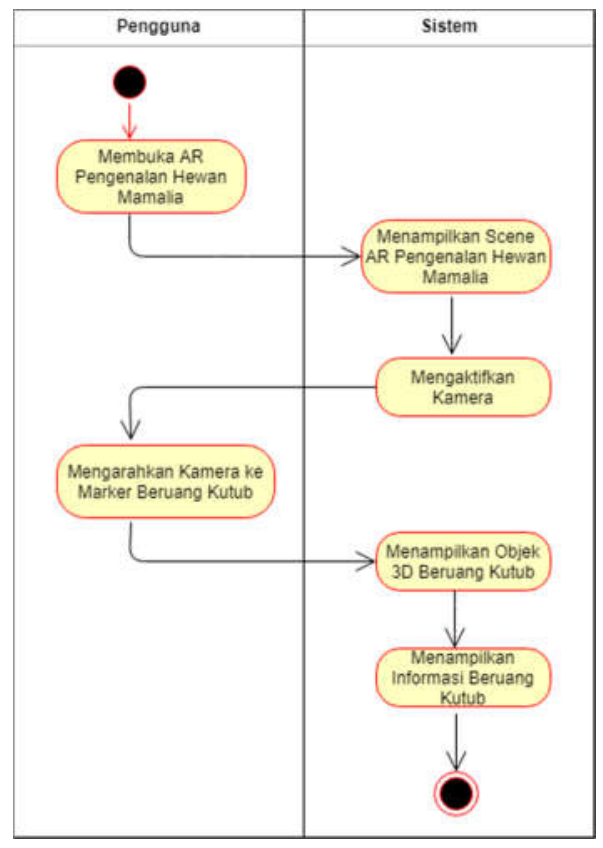

Gambar 2 Activity Diagram

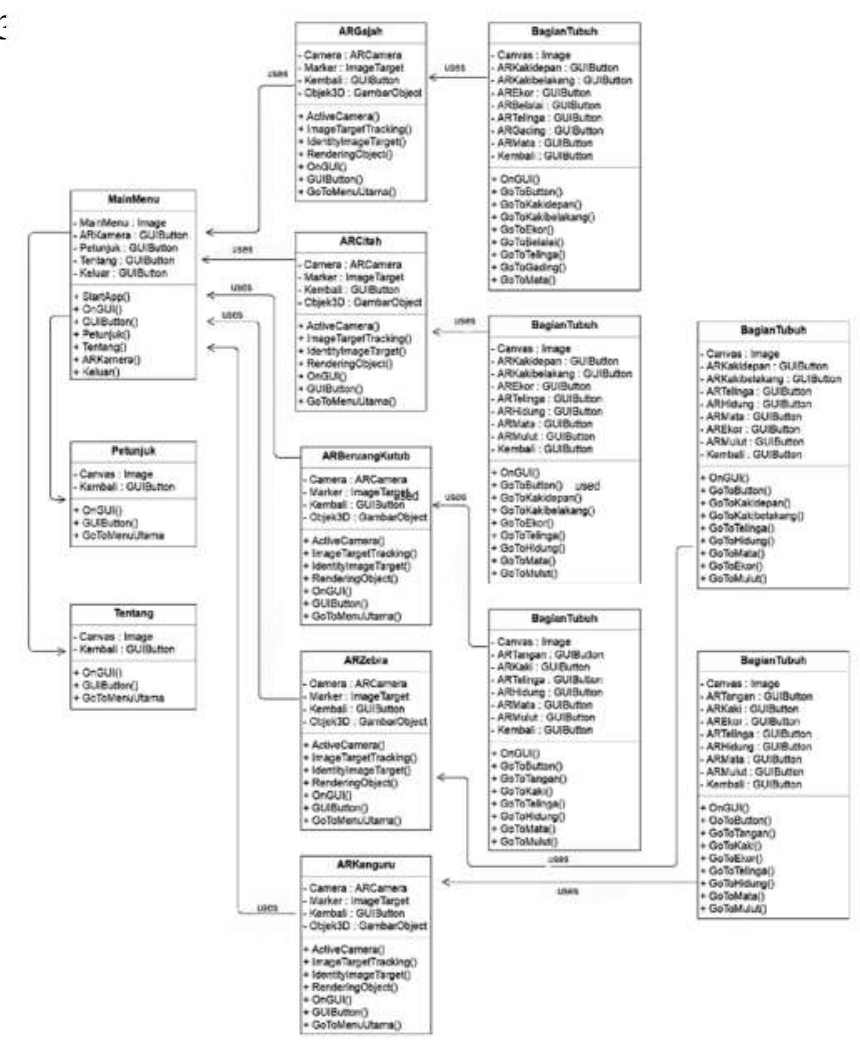

Gambar 3 Class Diagram 


\section{Perancangan Antar Muka}

Aplikasi Augmented Reality yang dibangun menggunakan Unity dengan sistem operasi Android dan memiliki beberapa tampilan scene yang disesuaikan dengan menu-menu aplikasi yang ada. Struktur antarmuka dari aplikasi dapat dilihat pada Gambar 4 berikut ini.

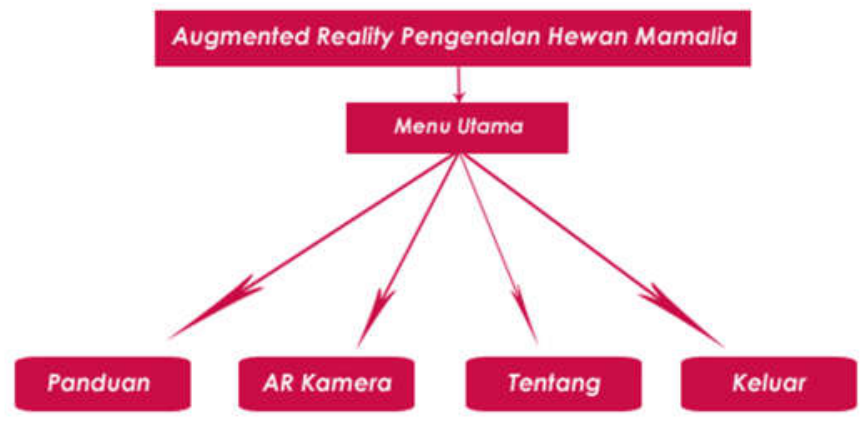

Gambar 4. Desain Antar Muka

\section{HASIL DAN ANALISIS}

A. Antarmuka Menu Utama

Antarmuka pada aplikasi ini dapat dilihat pada Gambar 5 dan Gambar 6.

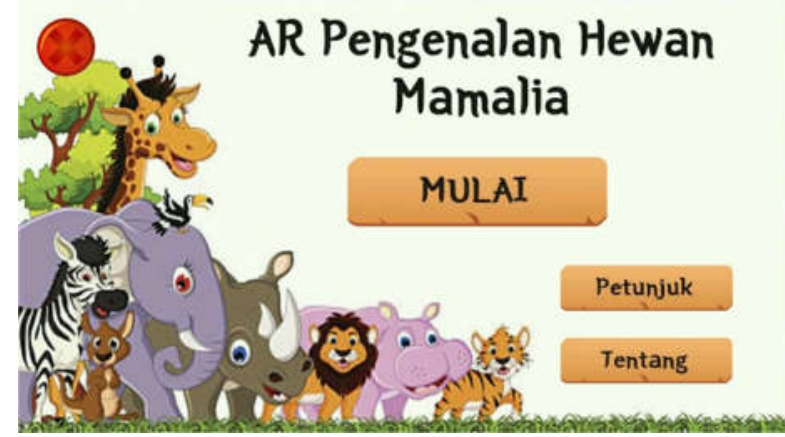

Gambar 5 Scene Menu Utama

Menu utama terdapat Mulai, petunjuk atau cara menggunakan aplikasi, tentang aplikasi dan keluar.

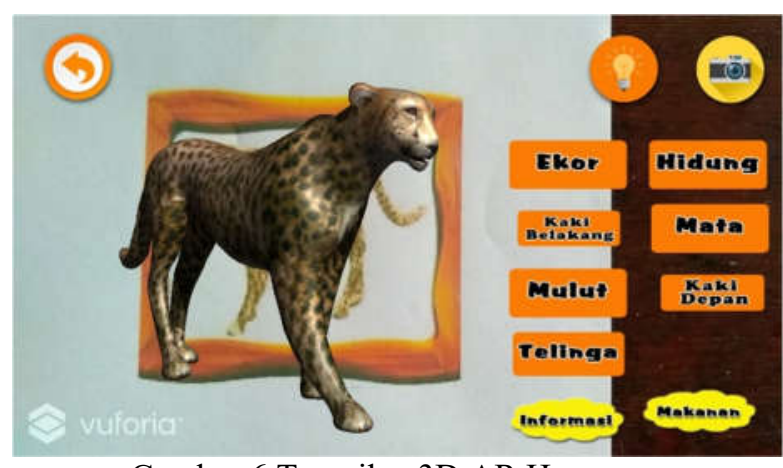

Gambar 6 Tampilan 3D AR Hewan

\section{B. Pengujian Jarak dan Ukuran Marker}

Pengujian jarak dilakukan untuk mendapatkan posisi yang optimal antara marker dan smartphone. Jarak marker dianalisis dengan parameter pixel yakni pada ukuran 32x50px maka marker tidak dapat dideteksi sementara akan tetapi, agar marker dapat dideteksi minimal menggunakan ukuran 96x150px dengan jarak minimum $14 \mathrm{~cm}$ dan maksimum $86 \mathrm{~cm}$. Semakin terlihat pixel pada marker maka semakin berpengaruh pada sistem untuk menampilkan objek 3D[5].

\section{Pengujian Kompabilitas}

Pengujian Kompatibilitas digunakan untuk memeriksa apakah perangkat lunak yang dikembangkan mampu berjalan pada hardware, sistem operasi, aplikasi, ataupun lingkungan jaringan yang berbeda. Semakin aplikasi dapat berjalan di banyak jenis perangkat yang berbeda, maka semakin baik aspek kompatibilitasnya. Hasil pengujian kompabilitas dapat dilihat pada Tabel 1.

Tabel 1 Hasil Pengujian Kompabilitas

\begin{tabular}{|c|c|c|c|c|}
\hline $\mathrm{N}_{0}$ & Yerk Perasktat & Lagr das Kamen & Yersi.Android & Keteraszan \\
\hline 1 & $x \operatorname{sen} 3 x$ & $\begin{array}{l}\text { Lox } 5 \text { incber, } \\
13 \text { segapites }\end{array}$ & $\begin{array}{c}60 \\
\text { (Noritmaliov) }\end{array}$ & $\begin{array}{l}\text { Bgihat } \\
\text { Begitan }\end{array}$ \\
\hline 2 & Adran isC Phas & $\begin{array}{l}\text { Laxt S itaber, } \\
\text { Smeppiats }\end{array}$ & $\begin{array}{c}5.1 \\
\text { (Lallpep) }\end{array}$ & $\begin{array}{l}\text { Bethat } \\
\text { Bepina }\end{array}$ \\
\hline 3 & Qmes. A37 & 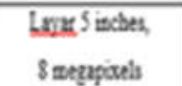 & $\begin{array}{c}5.1 \\
\text { (Lollpep) }\end{array}$ & Beitas \\
\hline 4 & Learo A6000 & $\begin{array}{l}\text { Inex Sincbes, } \\
8 \text { mezpopixts }\end{array}$ & $\begin{array}{c}42 \\
(x \in x=1)\end{array}$ & Begitats \\
\hline 5 & $\begin{array}{l}\text { Asw Zesisen Zoven } \\
\text { the }\end{array}$ & 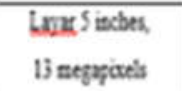 & $\begin{array}{c}60 \\
\text { (Mrribnaliow) }\end{array}$ & $\begin{array}{l}\text { Boblosi } \\
\text { Beping }\end{array}$ \\
\hline 6 & $\begin{array}{l}\text { Sensuag Giluxy } \\
\text { Gred Dosu }\end{array}$ & 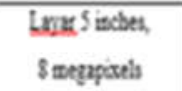 & $\begin{array}{c}5.0 \\
\text { (Lallpep) }\end{array}$ & $\begin{array}{l}\text { Afilin: } \\
\text { Becila }\end{array}$ \\
\hline 7 & $\begin{array}{l}\text { Xaveni Rodai Note } \\
4\end{array}$ & $\begin{array}{l}\text { Lxy } 53 \text { acter } \\
13 \text { etgapats }\end{array}$ & $\begin{array}{c}6.0 \\
\text { (Ner:hmallow) }\end{array}$ & $\begin{array}{l}\text { Belihas } \\
\text { Besitin }\end{array}$ \\
\hline 8 & $\begin{array}{l}\text { Xiscai Redeni } 4 \\
(4 x)\end{array}$ & $\begin{array}{l}\text { Lox S isches, } \\
13 \text { ecgapicts }\end{array}$ & $\begin{array}{c}6.0 .1 \\
\text { (Usrimaliow) }\end{array}$ & dothis \\
\hline 9 & $\operatorname{lng} 51$ & $\begin{array}{l}\text { Laxt S itches, } \\
13 \text { megricteds }\end{array}$ & $\begin{array}{c}5.1 \\
(\operatorname{Lal} l p e p)\end{array}$ & $\begin{array}{l}\text { Aptihsi } \\
\text { Bevilua }\end{array}$ \\
\hline 10 & Qmass 53 & 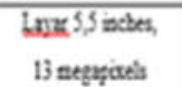 & $\begin{array}{c}60 \\
\text { (Mrsiknalisw) }\end{array}$ & 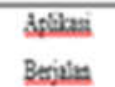 \\
\hline
\end{tabular}

\section{Pengujian Validity}

Pengujian Validity dilakukan untuk mengetahui respon pengguna terhadap kegunaan aplikasi AR Pengenalan Hewan Mamalia. Pengujian ini dilakukan kepada 30 orang responden terdiri dari anak-anak usia 7 hingga 12 tahun yang didampingi oleh orang tua. Semua responden bisa menggunakan aplikasi ini. Setelah 
responden selesai menggunakan aplikasi, maka setiap orangtua yang mendampingi anaknya diwajibkan untuk mengisi angket yang terdiri dari 10 pertanyaan dengan poin jawaban 4, 3, 2, 1 atau Sangat Baik (SB), Baik (B), Kurang (K) dan Sangat Kurang (SK) sesuai dengan respon anak ketika menggunakan aplikasi. Angket tersebut akan dihitung sehingga menghasilkan persentase dengan metode Linkert. dapat dilihat pada Tabel 2 berikut ini.

Tabel 2 Persentase Hasil Pengujian Validity

\begin{tabular}{|c|l|c|}
\hline Nilai Persamaan & f & n \\
\hline 4 & 273 & 300 \\
\hline 3 & 27 & 300 \\
\hline 2 & 0 & 300 \\
\hline 1 & 0 & 300 \\
\hline
\end{tabular}

Dari Tabel 2 diketahui sebagai berikut:

Untuk poin 4 atau Sangat Baik (SB)

$\mathrm{p}(100 \%)=273 / 300 * 100 \%=91 \%$

Untuk poin 3 atau Baik (B)

$\mathrm{p}(100 \%)=27 / 300 * 100 \%=9 \%$

Untuk poin 2 atau Kurang (K)

$\mathrm{p}(100 \%)=0 / 300 * 100 \%=0 \%$

Untuk poin 1 atau Sangat Kurang (SK)

$\mathrm{p}(100 \%)=0 / 300 * 100 \%=0 \%$

Maka, hasil persentase pengujian Validity adalah poin 4 atau Sangat Baik (SB) memiliki persentase $91 \%$, poin 3 atau Baik (B) adalah 9\% dan poin 2 atau Kurang 0\% serta poin 1 atau Sangat Kurang (SK) adalah $0 \%$. Nilai $9 \%$ pada poin 3 atau Baik yang diberikan oleh responden adalah karena aplikasi ini menampilkan semua objek hewan mamalia dengan ukuran yang sama dan tidak menampilkan lingkungan hidup hewan secara lengkap. Akan tetapi, tidak ada responden yang menilai aplikasi kurang atau sangat kurang karena aplikasi ini telah menjawab kebutuhan pengguna dan perangkat lunak. Sehingga hasil persentase akhir pengujian Validity tersebut menunjukkan bahwa aplikasi AR Pengenalan Hewan Mamalia mendapat respon sangat baik dari pengguna. Dari 10 elemen pertanyaan yang diisi oleh 30 orang responden mendapatkan hasil yang sangat baik yaitu dengan skor akhir 91\%. Hal ini menunjukkan bahwa pengguna dapat menggunakan aplikasi ini untuk mengenal hewan mamalia.

\section{E. Analisis Hasil Pengujian}

Dari pengujian jarak dan ukuran marker, jarak marker dianalisis dengan parameter pixel yakni pada ukuran 32x50px maka marker tidak dapat dideteksi sementara akan tetapi, agar marker dapat dideteksi minimal menggunakan ukuran 96x150px dengan jarak minimum $14 \mathrm{~cm}$ dan maksimum $86 \mathrm{~cm}$. Semakin terlihat pixel pada marker maka semakin berpengaruh pada sistem untuk menampilkan objek 3D.
Dari pengujian Kompabilitas disimpulkan bahwa aplikasi AR Pengenalan Hewan Mamalia dapat beroperasi untuk semua smartphone android dari versi 4.2 (KitKat) hingga 6.1 (Marsmellow). Aplikasi ini dapat berjalan dengan baik meski respon setiap smartphone tidak sama. Hal ini dipengaruhi oleh spesifikasi dari smartphone tersebut, semakin tinggi resolusi kameranya maka semakin baik proses pendeteksian markernya.

Berdasarkan pengujian Validity, pengguna dapat memperoleh informasi dari hewan yang dikenalkan tersebut, mulai dari bagian tubuh hingga makanannya. Akan tetapi, 9\% responden memberikan nilai Baik terhadap aplikasi ini karena aplikasi AR Pengenalan Hewan Mamalia menampilkan ukuran yang sama terhadap semua objek dan aplikasi ini tidak menampilkan lingkungan hidup hewan secara lengkap. Namun, hasil persentase akhir dengan nilai Sangat Baik adalah 91\% menunjukkan bahwa aplikasi AR Pengenalan Hewan Mamalia dapat digunakan untuk mengenal hewan mamalia yakni gajah, zebra, kanguru, citah, dan beruang kutub. Aplikasi yang disertai dengan suara ini juga menambah kemudahan pengguna untuk menangkap informasi yang disampaikan. Hadirnya tombol lampu membuat pengguna dapat menggunakan aplikasi di tempat dengan pencahayaan yang kurang terang sehingga marker tetap dapat dideteksi dengan baik.

\section{KESIMPULAN DAN SARAN}

A. Kesimpulan

Berdasarkan hasil implementasi dan hasil analisis pengujian yang dilakukan terhadap aplikasi Augmented Reality Pengenalan Hewan Mamalia dapat disimpulkan bahwa: 1. Aplikasi AR Pengenalan Hewan Mamalia dapat digunakan oleh pengguna untuk mengenal hewan mamalia. Pengguna dapat mengetahui bagian tubuh hewan, tempat hidup, dan juga makanan tersebut. Hal ini berdasarkan pengujian kuesioner dengan mengacu pada kebutuhan pengguna terhadap aplikasi.

2. Aplikasi AR Pengenalan Hewan Mamalia dapat dimanfaatkan pengguna sebagai media untuk mengenal hewan mamalia. Berdasarkan pengujian Validity dengan melihat respon pengguna terhadap kegunaan aplikasi, dimana 91\% responden menjawab Sangat Baik terhadap aplikasi ini dan menjawab kebutuhan pengguna untuk mengenal hewan mamalia yakni zebra, gajah, kanguru, beruang kutub, dan citah dengan aplikasi AR Pengenalan Hewan Mamalia. Akan tetapi, terdapat 9\% responden memberikan nilai Baik terhadap aplikasi ini karena setiap objek memiliki ukuran yang sama dan tidak menampilkan lingkungan hewan secara lengkap.

3. Hasil pengujian kompabilitas, aplikasi AR Pengenalan Hewan Mamalia dapat digunakan pada smartphone android minimal versi KitKat. 
B. Saran

Hal-hal yang menjadi saran dalam pengembangan aplikasi ini adalah:

1. Menambahkan bagian tubuh secara detail untuk dikenalkan terhadap hewan mamalia yang ada.

2. Menambahkan skala 3D untuk setiap objek hewannya.

3. Menampilkan lingkungan hidup setiap hewan secara lengkap.

\section{REFERENSI}

[1] Aplikasi Media Pembelajaran Biologi Sistem Saraf Pusat Menggunakan Augmented Reality JEPIN (Jurnal Edukasi dan Penelitian Informatika) Vol 4, No 1 (2018): Volume 4 No 1

[2] Perkembangan Teknologi Augmented Reality Sebagai Media Pembelajaran Interaktif Pada Mata Kuliah Kimia Dasar. Jurnal COMIT. Vol IX, No 1 (2016)

[3] Haller dkk. 2007. Augmented Reality. Emerging Technologies of Augmented Reality: Interfaces and Design.

[4] Andrayani Anggi. 2010. Sejarah Augmented Reality.Yogyakarta :Informatika

[5] Maulana Angga. 2014. Aplikasi Augmented Reality sebagai Media Pembelajaran Tata Surya. Jurnal KOMMIT. Vol 8.

[6] Mustika. 2016. Implementasi Augmented Reality sebagai Media Pembelajaran Interaktif. Citec Journal. Vol 2, No 4.

[7] Syahrin Alfi. 2016. Analisis dan Implementasi Metode Marker Base Tracking Pada Augmented Reality Pembelajaran Buah-buahan. Jurnal KOMPUTA. Vol 5, No 1.

[8] Azuma, R T. (2007). A survey of augmented reality. Massachusetts Institute of Technology, 6 (4): 355-356.

[9] Wahadyo Agus. 2013. Android untuk Pengguna Pemula Tablet dan Handphone. Jakarta: Mediakita.

[10] Dharwiyanti Sri. 2003. Pengantar Unified Modeling Language (UML). IlmuKomputer.com

[11] Blender.org.2013. About. https://www.blender.org/about/. diakses pada tanggal 1 Juni 2017

[12] Tama. 2017. Kegunaan Aplikasi Blender. Jakarta: Cipta Media

[13] Implementasi Markerless Augmented Reality Sebagai Media Informasi Koleksi Museum Berbasis Android (Studi Kasus: Museum Kalimantan Barat), Jurnal Sistem dan Teknologi Informasi (JustIN), Vol 4, 239-245

[14] Roedavan, Rickman. 2014. UNITY Tutorial Game Engine. Bandung: Informatika Bandung.

[15] Unity3d.com. 2014. Project. https://unity3d.com/Project. diakses pada tanggal 7 Juli 2018

[16] Al-Maqassary Ardi. 2013. Pengertian Hewan Mamalia. Jakarta: Bindo

[17] Validity. 2014. Uji Validity. https://www.binus.ac.id diakses pada tanggal 10 April 2018

[18] Sugiono. 2012. Metode Penelitian Kuantitaif, Kaulitatif dan $R \& D$. Bandung: Alfabeta

[19] Pemodelan UML Sistem Informasi Monitoring Penjualan Dan Stok Barang. Jurnal Khatulistiwa Informatika, Vol IV, No 2

[20] Adytia. 2010. Fungsi Activity Diagram. Bandung: Informatika

[21] Ilham Efendi. 2015. Tipe Diagram UML. Jakarta: Bindo 